\title{
The Decision to close an Area Mental Hospital
}

\author{
An inside view \\ A. I. Garelick, Consultant Psychotherapist, Claybury Hospital, Woodford Green, Essex
}

This paper has been prompted by the decision to close a large psychiatric hospital in its entirety and reprovide its services within the community. This was announced in 1983 with the aim that it would be effected within a ten year period. The hospital at that time had approximately 1,000 patients and the decision, which came as a shock to the staff, was taken not by the local management or clinicians but by the more distant administrative structure.

Closure was to be the means by which a quantum leap in the provision of mental health services was to be effected. The plan was presented as a vision and a new philosophy full of laudable principles. There was a conviction that the programme could be self financing and that by doing away with large Victorian institutions enormous resources would be unlocked and everybody would be better off.

When the staff actually involved in the clinical care of patients began to look at the proposals realistically they conveyed their impression that the plans were wildly overoptimistic. This provoked tremendous hostility from those who presented it. A split developed in which anybody questioning or doubting the proposals was branded as a reactionary, a Luddite and an agent trying to destroy a radical and innovative programme. ${ }^{1.2}$ Two camps emerged, the first consisting of enthusiasts for the scheme, who tended to be non-clinicians and from outside the mental health services; the other camp contained mainly health professionals who were in daily contact with the patients, principally doctors and nurses.

The protagonists of the scheme pressed ahead with their plans, the community became good and the hospital became bad and this accentuated the split between the two camps. This situation has been further exacerbated by recent administrative changes, since each district has been invited to plan its own autonomous service (with the implicit de-centralisation of planning). District administrations tend to be more remote and thus to have less knowledge of the hospital and its population. This has reinforced a common fantasy that the hospital was sitting on a pot of gold. As a consequence tremendous excitement and enthusiasm has been generated in the user districts that there are piles of spoils to be divided amongst them as a result of the complete closure of the hospital.

There was a striking difference in the demeanour of the two camps. The enthusiastic protagonists, full of optimism and excitment generating planning documents by the ream, conveyed a conviction that they had found the answer. They had a sense of power, a sense that they had within them the wisdom and the method to cure all problems. Their medical colleagues were seen very much in disparaging terms as somewhat incompetent, and ignored. The other camp, consisting of clinicians, looked extremely apprehensive, anxious, sceptical, pessimistic and depressed. Little meaningful communication took place between the two groups. There was a sense in the initial stages that the clinicians would be obstructive, a nuisance and interfere with the speedy execution of the new service; no communication was the solution. Such was the power of this phenomenon that there seemed to be an obliteration of any awareness of the history of, or recent developments in, psychiatric services.

It is instructive to look at what took place in the 18 th and 19th centuries regarding mental health developments. ${ }^{3.4 .5}$ At that time such terms as moral insanity and moral degeneracy were used and reformers were committed to improving the lot of the mentally ill. A driving motive of the reformers was to remove people from poor physical surroundings and from the workhouses and gaols and thus improve the lot of these "pauper lunatics". By removing them from bad moral influences and giving them fresh air, a healthy environment, exercise, hard work, regular prayer and spiritual guidance, the shattered barque of the mind might mend.

A famous example is that of the Quaker Retreat in York which was conceived by William Tuke in 1792 . It seems to me that in some ways the proponents of community care are rather mirroring this type of thinking, except that the Quaker ethic has been replaced by a contemporary materialistic ethic: if you provide pleasant surroundings and a good material environment, all will be well. There appeared to be a parallel between the reformers of the 18th and 19th century and the current planners who both have the desire to improve the lot of the mentally ill. They have used the same arguments, but reached opposite conclusions. In the 18th and 19th centuries they built asylums; now we are demolishing them.

The York Retreat was held up at the time as a model of the efficacy of moral treatment. It is important to note, however, that the Retreat had only 30 patients and was in its early years a purely Quaker establishment. Moreover, the Retreat did not accept pauper lunatics; they were all accommodated in the nearby York asylum. It has been clearly documented how from the ideal conception, as recommended by Tuke and by the pioneering attempts of 
Conolly at Hanwell, there was a remorseless rise in the number of people who were referred. A complex interaction of social, political and economic factors soon overwhelmed any idealistic momentum that had initiated the development of the asylum system and large institutions of over 2,000 patients were soon in existence.

Later developments also do not appear to have been considered. In the post-war period there has been a gradual transformation in the practice of psychiatry resulting in a slowly decreasing reliance on the hospital as the sole medium of treatment. These changes are reflected in the decreasing number of patients in the large mental hospitals. But this progression has been fraught with difficulties and punctuated with overoptimistic claims by those involved in the newly developing modes of treatment. Furthermore, the attempt to develop services in the community has encountered great difficulties and resistance. For many years there have been well-known problems, such as the shortage of Part III accommodation and the difficulty of obtaining suitable accommodation for after-care.

Similarly there has been no appreciation of the contemporary experience abroad regarding hospital closure, such as in the United States or Italy where many of the difficulties have been well documented. ${ }^{6.7 .8}$

The sequence of events that I have described has provoked in me a curiosity about the process and a sense of déjà $v u$. Why has there been so little learning from history and why have the opinions of clinicians been ignored?

As a clinician myself, I would like to offer some thoughts on the matter. The idea of asylum, that a place is required for people who cannot survive in open society, has been given no value in the present planning. An important aspect of the asylum principle is that it protects patients from the tremendous pressure to make them "better", whatever that means, which in itself can in many cases be countertherapeutic. An important component of an asylum is the capacity not to persecute somebody with therapeutic ambition which is a need of the health professional rather than that of the afflicted patient.

The second issue is that institutions and institutionalisation are being seen as the major factor in the creation of morbidity among a certain category of patients. ${ }^{9}$ This is not to deny that institutions can have adverse effects on patients or staff. One has only to look at the paucity of care for the staff within contemporary institutions and the consequent effect on morale. This way of thinking, however, ignores the effect that patients have on staff and on the institution itself, e.g. schizophrenics with chronic states of apathy. A moulding takes place from the interaction of patients with staff which results in a modus vivendi. This interaction has been ignored and the emphasis has been on a unitary notion of the badness of institutions. The consequent focus on community care is that with pleasant environmental conditions and effort and kindness, a process of "normalisation" will occur in which the afflicted individual will be reintegrated into society. The questions that do not seem to have been asked are - why are the long-stay wards as they are? Why are they not comfortable and homely? My impression is that instead of addressing such questions managers and planners have refused to face them and are industriously planning new ventures in the community.

This situation with its accompanying excitement can be compared to what takes place in a clinical setting, where a patient presents in a manic state. Some of the characteristics of such a patient are: a state of elation or excitement out of keeping with their personal circumstances, which may be associated with grandiose ideas, impaired judgement and over-activity. There may be unshakeable optimism and infectious enthusiasm. If opposed they often become querulous and serious consideration of their actual difficulties are dismissed or denied. In a flush of manic excitement the patient feels good and wants nothing to do with the reality around him which he experiences as depressing and persecutory. We recognise that it is difficult to engage such a manic patient in any kind of therapeutic alliance.

There have been similar difficulties in respect to the planning process. The lack of rigorous thought has the hallmarks of a manic solution to a problem. It is a manic form of reparation since it does not deal with the underlying problems and therefore leads to further cycles of maladaptive behaviour. Hannah Segal describes the manic phenomenon with great clarity. "Manic reparation is a defence in that its aim is to repair the object in such a way that guilt and loss are never experienced." 10

The underlying problem is painfully clear: mental health provision has always been run on a shoestring budget and over the last two decades the service has been near to breaking point, something of which the authorities are well aware. This is indicated by the development of the Yates Indices, prepared by John Yates of the School of Health Management at Birmingham University. He has identified six variables which are potential risk factors in hospitals that have had scandals which resulted in public enquiries. These are meant to provide a "scandal predictor". These indicators show that it is the most under-resourced hospitals, with the worse ratio of staff to patients that are at risk. A conclusion of such findings would be to increase the resources needed to improve the ratio of staff to patients. A plausible hypothesis is that management, faced with the impossible constraint of not having sufficient resources on the one hand and a fear of a scandal breaking out on the other, find themselves in an uncomfortable position. Something has to give and that something has resulted in the generating of a manic solution.

At present the fragile fabric of the mental health service is suffering serious damage, particularly the morale of the staff who are struggling with disabled people who society would prefer to forget. Consequently, the capacity to maintain a comprehensive service is being undermined. Slowly but remorselessly many practical issues have begun to bring the realities of the situation home to the planners. The familiar problems of finance, staffing, difficulties of obtaining sites, planning permission, resistance of local communities, and the vulnerability of many of our patients are now in view and clearly the mood has begun to change. 
Many planners have felt more anxious and burdened and the clinicians have felt correspondingly less oppressed and perhaps this is allowing both groups more opportunity for reflection on the future pattern of service. Since there is now more contact with reality it may be possible for a dialogue to develop, although it is doubtful whether it will lead to substantive changes in the plans.

It is difficult to say what the future holds. At the moment it looks as though there are new developments on the horizon, but the acid test is whether they will be sustained. The reality is that for all we have gone through only a small number of patients, by no means the most disabled, have left the hospital. Furthermore, as the diffculties and realities are striking home, the prospect of transinstitutionalisation is becoming more and more real. While initially there was an anxiety that the long-stay wards would merely be re-created in the community, another more formal type of institutionalisation is becoming apparent. As the implementation of community care becomes more problematic and expensive, small hospitals are being earmarked for combined use for mental health, mental handicap and psychogeriatric services. The old mental hospital philosophy is alive, but is likely to appear in a new suit of clothing, without the grandeur or the grounds of the existing Victorian asylums.

In 1983 we were given the answer "The hospital will close". This was rather like the situation in the Hitch Hiker's
Guide to the Galaxy where the answer was 42 . The problem is what is the question?

\section{ACKNOWLEDGEMENTS}

I would like to thank Professor Kathleen Jones and Hemda Garelick for their helpful comments.

\section{REFERENCES}

${ }^{1}$ JAQUES, E. (1955) Social systems as a defence against persecutory and depressive anxiety. In New Directions in Psychoanalysis. London: Tavistock.

${ }^{2}$ Menzies, Isobel, E. P. (1960) A case study in the functioning of social systems as a defence against anxiety. Human Relations, 13, 95-121.

${ }^{3}$ JoNES, K. (1955) Law, Lunacy and Conscience 1744-1845. London: Routledge \& Kegan Paul.

${ }^{4}$ SCuli, ANDrew T. (1979) Museums of Madness. London: Allen Lane.

${ }^{5}$ Goffman, E. (1961) Asylums. London: Anchor Books, Doubleday \& Co. Reprinted as a Pelican Book (1968).

6JONES, K. (1985) After Hospital: A Study of Long-Term Psychiatric Patients in York. University of York.

7__ \& Poletr1, A. (1985) Understanding the Italian experience. British Journal of Psychiatry, 146, 341-347.

8 _ \& _ (1986) The Italian experience reconsidered. British Journal of Psychiatry, 148, 144-150.

${ }^{9}$ Goffman, E. (1982) In Psycho Politics (P. Sedgwick). London: Pluto Press.

${ }^{10}$ Segal, H. (1973) Manic defences. In Introduction to the Work of Melanie Klein. London: Hogarth and the Institute of Psychoanalysis.

\section{The World Society of Victimology (WSV)}

The WSV is a non profit-making, non-governmental organisation. Its members, brought together from around the world by their mutual concern for victims, include victim assistance practitioners, lawyers, social workers, physicians, professors and students. Its purposes are to promote research about victims, to assist victims and advocate their interests throughout the world; to encourage interdisciplinary and comparative research in victimology; and to advance the co-operation of international, regional, and local agencies, groups and individuals concerned with the problems of victims.

The WSV sponsors symposia, workshops and seminars, including an International Symposium on Victimology every three years. It also sponsors the International Review of Victimology to encourage the exchange of theories and research and to foster the discussion of victim service projects. The WSV Newsletter keeps the membership informed of major activities relating to victims and an International Bibliography has been established to facilitate access to the growing literature on victims.

Those wishing to become members should write to Prof. Dr. Hans Joachim Schneider, Director, Department of Criminology, University of Westphalia, 24/25 Bispinghoff, D-4400 Muenster/Westphalia, Federal Republic of Germany.

\section{Rehabilitation Centre for Torture Victims (RCT)}

The RCT is a private foundation based in Denmark, financed by government funds and private donations. Its aims are to run a centre for the rehabilitation of people who have been subjected to torture and their families; to instruct health personnel in the examination and treatment of those who have been subjected to torture; to engage in research on torture and on the nature and extent of its consequences for the purposes of treatment and eventual abolition; and to set up an international documentation centre for registration of facts about torture and its effects. Further information: RCT, Juliane Maries Vej 34, DK-2100 Copenhagen Ø, Denmark. 